\title{
Expression and Regulation of Dickkopf2 During Periimplantation in Mice
}

\author{
Ying ZHANG ${ }^{1,2)}$, Sha PENG ${ }^{1,2)}$, Haibin KUANG ${ }^{1,2)}$, Qi CHEN ${ }^{1,2)}$, Shuang LIU $^{1,2)}$, Li ZHANG ${ }^{1,2)}$ \\ and Enkui DUAN ${ }^{1}$ ) \\ 1) State Key Laboratory of Reproductive Biology, Institute of Zoology, Chinese Academy of Sciences, Beijing 100101 and \\ ${ }^{2)}$ Graduate School of the Chinese Academy of Sciences, Beijing 100039, China
}

\begin{abstract}
Successful implantation depends on active dialogue between the maternal endometrium and the implanting blastocysts that is well controlled by groups of regulators at the molecular level. Dickkopf2 (Dkk2) is a member of Dickkopf family normally acting as an antagonist of canonical Wnt/beta-catenin signaling, which has been proven to participate in tumorigenesis and early embryo development. In order to explore the potential function of Dkk2 in embryo implantation, the present study investigated the uterine expression and regulation profiles of Dkk2 during periimplantation in mice. Using reverse transcription-polymerase chain reaction, immunohistochemistry and Western blotting, we showed that the mRNA and protein levels of Dkk2 began to increase in the glandular epithelium on day 4 , continued to increase on day 5 and then decreased from day 6 of pregnancy. Moreover, on days 5-8 of pregnancy, Dkk2 was increasingly expressed in the deciduum of the uterus, especially around the implanting embryos. In addition, upregulation of Dkk2 was also observed in uteri treated with estrogen (estradiol-17 $\beta$ ) as well as in oil-induced artificial decidualization, indicating that the expression of Dkk2 could be induced by both steroid hormone (estrogen) and the process of decidualization. Furthermore, in the postimplantation uterus, the Dkk2 protein showed an inversed expression with active beta-catenin from day 6 onward, supporting the notion that Dkk2 plays an inhibitory role against canonical Wnt signaling in the context of the decidualizing stroma. Collectively, our data suggests that Dkk2 expression is associated with uterine receptivity changes as well as the process of decidualization and that it might play important roles through inhibition of canonical Wnt signaling in the periimplantation uterus.
\end{abstract}

Key words: Decidualization, Dickkopf2 (Dkk2), Implantation, Mouse, Uterus

(J. Reprod. Dev. 55: 17-22, 2009)

Ш nt signaling pathways play important roles in various processes such as fetal development, tumorigenesis and homeostasis. When Wnt ligands bind to two receptors, Frizzled (Fz) proteins and lipoprotein receptor-relate proteins 5 and 6 (LRP5/6), classic canonical Wnt signaling is activated. As a result, beta-catenin accumulates in the cytoplasm, then translocates into the nucleus and finally activates the expression of diverse Wnt target genes [1]. The Wnt signaling pathway has been demonstrated to be involved in the female reproductive tract and to play important roles in mediating estrogen-induced uterine responses [2-5]. There is also evidence that some Wnt signaling related genes exhibit spatiotemporal expression in the uterus during mouse periimplantation and that they are tightly regulated by critical implantation-related genes, such as LIF and Hoxa-10 [6]. Furthermore, during mouse preimplantation embryo development and embryo activation, many Wnt signaling related genes show a dynamic expression pattern within the embryo that might determine the competency of blastocysts for implantation [7]. More recently, it has been demonstrated that embryo-derived Wnt7a can trigger an implantation-related response in the uterus, resulting uterine upregulation of nuclear beta-catenin, a downstream event of canonical Wnt signaling activation [8]. This evidence highlights Wnt signaling as an important participator in the context of

Accepted for publication: July 11, 2008

Published online in J-STAGE: August 8, 2008

Correspondence: E Duan (e-mail: duane@ioz.ac.cn) embryo-uterine interaction during early pregnancy.

Wnt activity can be inhibited by two main classes of antagonists. The first group consists of Wnt ligand binding proteins that are structurally similar to the extracellular domains of the Frizzled (Fz) family, which exert their functions by preventing extracellular Wnt ligands from interacting with Frizzled receptors. On the other hand, the second class of antagonists, including the Dickkopf (Dkk) family proteins, do not prevent Wnt from associating with Frizzled but directly interact with LRP5/6 coreceptors to form a ternary structure, resulting in a rapid removal of the receptors via Kremenmediated endocytosis.

Dkk2 is a member of Dkk family. It has recently been proposed that Dkk2 could normally act as a Wnt inhibitor by binding to Kremen2 (Krm2) and LRP5/6, and it appears to be involved in cell differentiation as well as epithelial-mesenchymal transformation [9-11]. This has raised our interest in determining whether Dkk2 plays an important role in embryo implantation by mediating Wnt signaling, since there have been other Wnt antagonists proven to play critical roles for the process of embryo implantation [12].

Previous work in our lab has confirmed that Dkk1 and its receptor Kremen1 played important roles during the implantation process in the mouse [13], and it has more recently been demonstrated that they could promote trophoblast cell invasion [14]. Due to the structural similarities and possible competitive/cooperative relationships of Dkk2 and Dkk1, investigation of the potential role of Dkk2 in embryo implantation is worthwhile. For this purpose, 
we investigated the distribution and regulation pattern of Dkk2 in murine uteri during periimplantation in the present study.

\section{Materials and Methods}

\section{Animals and treatments}

Adult mice (weight 22-25 g) of the outbred Kunming white strain were purchased from the Experimental Animal Center (Institute of Zoology, Chinese Academy of Sciences, Beijing, China) and raised at $25 \mathrm{C}$ with a constant photoperiod (14 h light:10 h dark cycle). The Guidelines for the Care and Use of Animals in Research were followed. Animals were allowed free access to water and food. Virgin female mice were mated with fertile or vasectomized males of the same strain. The presence of a vaginal plug was used to designate day 1 of pregnancy or pseudopregnancy. Pregnancy was confirmed by recovering embryos from the reproductive tracts during days 1-4 and the presence of implantation sites during pregnancy days 5-7. Uteri from days 1-5 of pseudopregnancy were collected for further analysis.

Artificial decidualization was induced by injection of $10 \mu \mathrm{l}$ sesame oil intraluminally into one uterine horn on day 4 of pseudopregnancy, whereas the contralateral horn without any infusion served as a control. Uterine tissues were collected on days 58 of pregnancy, and the decidualizing reaction was confirmed by increased uterine weight and histological examination.

To induce delayed implantation, pregnant mice were ovariectomized at $0800-0900 \mathrm{~h}$ on day 4 of pregnancy and maintained with a daily subcutaneous injection of progesterone (P4, $2 \mathrm{mg} / \mathrm{mouse}$ ) from days 5-7. These animals were divided into two groups: the activated group and the dormant group. To activate dormant blastocysts and initiate implantation, the activated group mice were injected with estradiol-17 $\beta$ (E2, $100 \mathrm{ng} /$ mouse) on day 7. Their uteri were collected after $24 \mathrm{~h}$ of treatment, and only uteri with implantation sites were used. In the other group, the P4-treated mice were sacrificed for uterus collection on day 7.

To determine the effects of steroid hormones (E2, P4) on the expression of Dkk2 in the uterus, mature female mice were ovariectomized. After a 2-week rest period, the ovariectomized mice were treated with an injection of estradiol-17 $\beta$ (E2, $100 \mathrm{ng} /$ mouse), progesterone (P4, $2 \mathrm{mg} / \mathrm{mouse}$ ) or a combination of the same doses of progesterone and estradiol-17 $\beta(\mathrm{E} 2+\mathrm{P} 4)$, respectively. The mice were sacrificed for uterus collection at 2, 4, 6, 12 and $24 \mathrm{~h}$ after the steroid hormone treatments. Estradiol- $17 \beta$ and progesterone were dissolved in sesame oil and injected SC and the controls received the sesame oil only.

\section{Reverse transcription-polymerase chain reaction}

Total RNAs were isolated from uteri with Trizol (Gibco BRL, Grand Island, NY, USA) reagent according to the manufacturer's instructions. A total of $2 \mu \mathrm{g}$ RNA was reversed transcribed using Moloney Murine Leukemia Virus Reverse Transcriptase (NEB, New England, USA) and $2 \mu$ g of random hexamer primers (Takara, Ohtsu, Japan). The primers used for amplifying mouse Dkk2 and $18 \mathrm{~s}$ were as follows: the sense and antisense primers for $D k k 2$ were 5-ACCCTTGCAGCAGTGATAAG-3 and 5-TGGCTTTGGAAGAGTAGGTG-3, respectively, and the sense and antisense primers for 18 s were 5-AATCAGGGTTCGATTCCGGA-3 and 5-CCAAGATCCAACTACGAGCT-3, respectively.

Amplifications were carried out with 30 cycles for Dkk2 and 28 cycles for $18 \mathrm{~s}$. The thermal cycling conditions were $94 \mathrm{C}$ for 30 sec, $58 \mathrm{C}$ for $30 \mathrm{sec}$ and $72 \mathrm{C}$ for $30 \mathrm{sec}$.

\section{Immunohistochemistry}

The procedures followed a protocol described previously [15]. Mouse uteri were cut into small pieces, fixed in Bouin's solution, dehydrated and embedded in paraffin as described previously [16]. Sections $(5 \mu \mathrm{m})$ were cut, deparaffinized and then rehydrated. Endogenous peroxidase activity was blocked by incubating the sections in 3\% hydrogen peroxide for $10 \mathrm{~min}$. Nonspecific binding was blocked in $10 \%$ normal goat serum in PBS for 40 min. The sections were then incubated with the Dkk2 (R\&D, Minneapolis, USA), Kremen2 (ZYMED, South San Francisco, California, USA) or active beta-catenin (Upstate, New York, USA) antibodies, respectively, overnight at $4 \mathrm{C}$, and were subsequently incubated with horseradish peroxidase-conjugated secondary antibodies (Zhongshan Biotechnology, Beijing, China) for $1 \mathrm{~h}$ at $37 \mathrm{C}$. The second antibody was detected with 3, 3'-diaminobenzidine solution (Zhongshan Biotechnology, Beijing, China). For some sections, primary antibodies were replaced with preimmune IgGs as negative controls.

\section{Western blot analysis}

The procedures for Western blot analysis followed a protocol described previously [13] with some modifications. Protein samples were boiled in SDS $\beta$-mercaptoethanol sample buffer, and 100 $\mu$ g samples were loaded onto each lane of $15 \%$ polyacrylamide gels. After separation by electrophoresis, proteins in the gels were blotted onto polyvinylidine difluoride membranes (Millipore, Billerica, MA, USA). After blocking with $5 \%$ fat-free milk diluted in TBS $+0.1 \%$ Tween-20 (TBST), the membranes were probed with the Dkk2 antibody (R\&D) at $4 \mathrm{C}$ overnight. Horseradish peroxidase-conjugated rabbit anti-goat IgG was then used to detect proteins by enhanced chemiluminescence (Zhongshan Biotechnology). Anti-beta-actin (Zhongshan Biotechnology) antibody was used in the same western blot as a loading control.

\section{Results}

\section{Expression of Dkk2 during the periimplantation period}

Since the $D k k 2$ transcripts have been detected in normal murine uteri [17], we first examined the expression pattern of Dkk2 mRNA during the mouse periimplantaion period by semiquantitative RTPCR. As shown in Fig. 1A, Dkk2 was undetectable from days 1 to 3 , whereas on day 4 of pregnancy, the level of $D k k 2$ mRNA was significantly increased. This high level lasted to day 7 of pregnancy, and the signal then decreased on day 8.

To further examine the localization of Dkk2 in the pregnant uterus, immunohistochemistry was performed from day 1 to day 8 . As shown in Fig. 1B, on day 1, a basal level of Dkk2 protein was detected localizing in both the luminal and glandular epithelium. On days 2 and 3, it was barely detectable in the uteri (data not shown), which was in agreement with our RT-PCR results. On day 


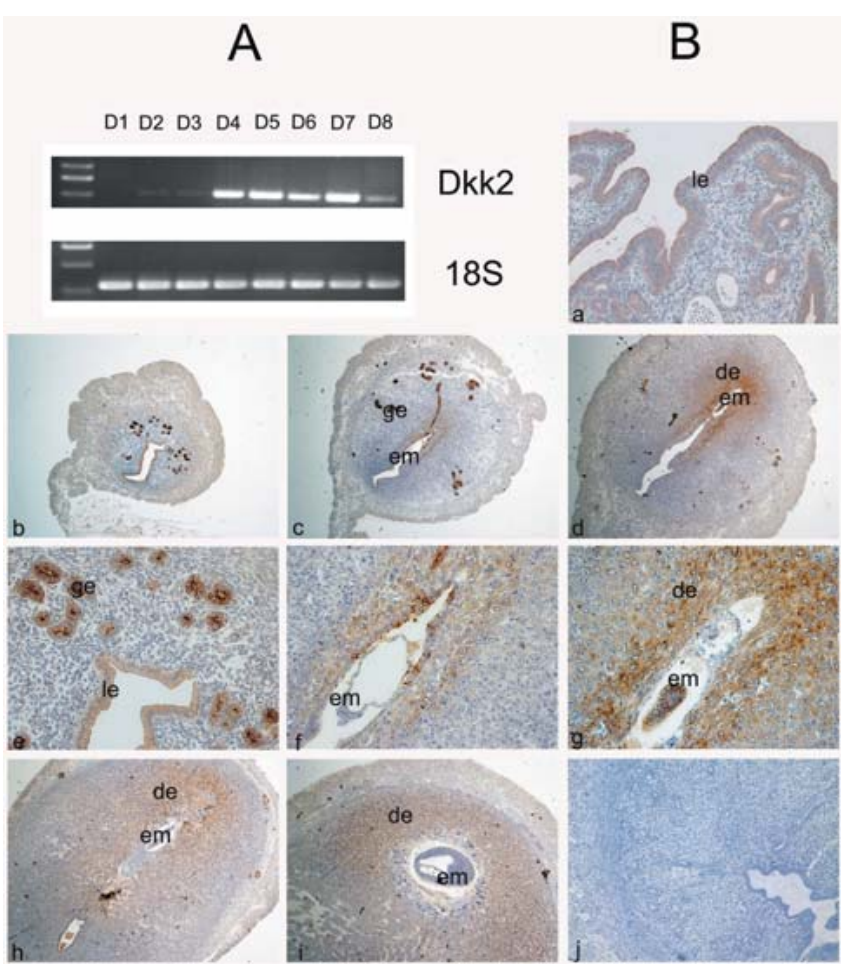

Fig. 1. Dkk2 expression in the uterus during the periimplantation period. A: RT-PCR analysis of Dkk2 (upper) and $18 S$ (lower) genes in mouse uteri from days 1 to 8 of pregnancy. B: Immunohistochemistry analysis of Dkk2 in mouse uteri during early pregnancy on day 1 (a), 4 (b and e), 5 (c and f), 6 (d and g), 7 (h) and 8 (i) and in the negative controls (primary antibody replaced by goat IgG; j). Cross-sections were used for all samples and are shown at $40 \times(\mathrm{b}, \mathrm{c}, \mathrm{d}, \mathrm{h}$ and $\mathrm{i}), 100 \times(\mathrm{a}, \mathrm{e}, \mathrm{f}, \mathrm{g}$ and $\mathrm{j}$ ), respectively. Le, luminal epithelium; ge, glandular epithelium; em, embryo; de, deciduas.

4 of pregnancy, a highly increased level of Dkk2 was observed, especially localized in the glandular epithelium. From day 5 onward, Dkk2 protein began to increase in the primary decidualization zone, initially around the implanting embryo, and this was followed by a rapid increase on days 6 to 8 in the decidualizing area. On the other hand, while the level of Dkk2 remained high in the glandular epithelia of day 5 uteri, it decreased significantly in the day 6 uteri. In fact, there were only small parts of the glandular epithelia of day 6 uteri that were still expressing Dkk2, and these parts exhibited much weaker staining.

\section{Expression of Dkk2 in pseudopregnant and delayed implantation mouse uteri}

The expression pattern of Dkk2 for days 1 to 4 of pseudopregnancy is similar to that for normal pregnancy. Nonetheless, on day 5 of pseudopregnancy with the absence of an implanting embryo, the expression of Dkk2 was significantly decreased in both the luminal and glandular epithelium compared with that of the normal pregnancy (only days 4 and 5 are shown in Fig. 2).

In the delayed implantation model, the uterus remains in the receptive state under the control of $\mathrm{P} 4$ while the blastocysts
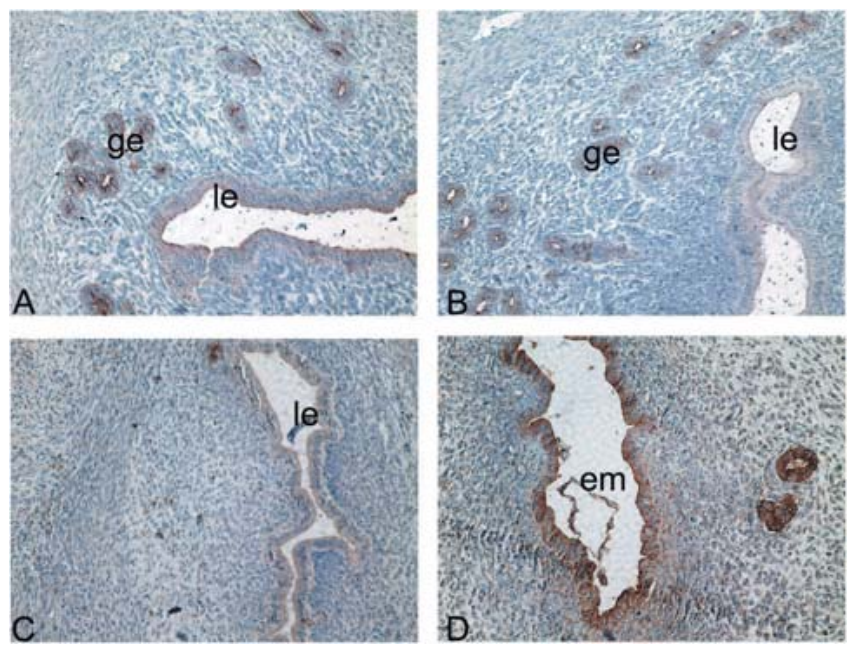

Fig. 2. Immunohistochemical analysis of Dkk2 protein during pseudopregnancy and delayed implantation. The expression patterns of Dkk2 on days 4 (A) and 5 (B) in pseudopregnant uteri, in the P4-treated delayed uterus on day 7 of pregnancy $(C)$, and at the implantation site after E2 treatment in the delayed uterus (D) are shown at their original magnification, $\times 200$.

undergo dormancy, and implantation does not occur until an estrogen injection rapidly activates the blastocysts. The P4-primed uteri contained a basal level of Dkk2 protein in the luminal epithelium (Fig. 2C). After embryo implantation was initiated by estrogen, Dkk2 protein was strongly detected in luminal epithelial cells along with an increasing density in the subepithelial stroma around the implantation chamber (Fig. 2D), and this was similar to the expression pattern observed on day 5 of pregnancy.

Expression of Dkk2 in mouse uterus of artificial decidualization

To determine whether embryonic signals influence the expression of Dkk2 during decidualization, artificial decidualization was induced in one uterine horn by intrauterine oil infusion on day 4 of pseudopregnancy, while the contralateral horn without treatment served as a control. Dkk2 protein was unobservable in the control uterine horn, while a remarkable signal could be detected in the decidualized cells that was maintained until day 8 of pseudopregnancy with artificial decidualization (Fig. 3), and this was similar to that observed in normal pregnancy from days 5 to 8 .

\section{Effects of steroid hormones on Dkk2 expression}

Dkk2 was notably induced on day 4 of pregnancy, at which point the uterus is exposed to rising levels of progesterone from corpora lutea with a small surge of estrogen. This expression pattern suggested that induction of Dkk2 might be regulated by steroid hormones. To validate this hypothesis, ovariectomized mice were treated with single injections of E2, P4 or a combination of E2 and P4 (E2+P4), respectively. As shown in Fig. 4, the level of Dkk2 protein was low in the uteri of ovariectomized animals. In the E2treated group (Fig. 4A), the protein level gradually increased after treatment, with a peak at $6 \mathrm{~h}$ post-injection, and this level lasted for 24 h. In the P4-treated group (Fig. 4B), there was no evident 

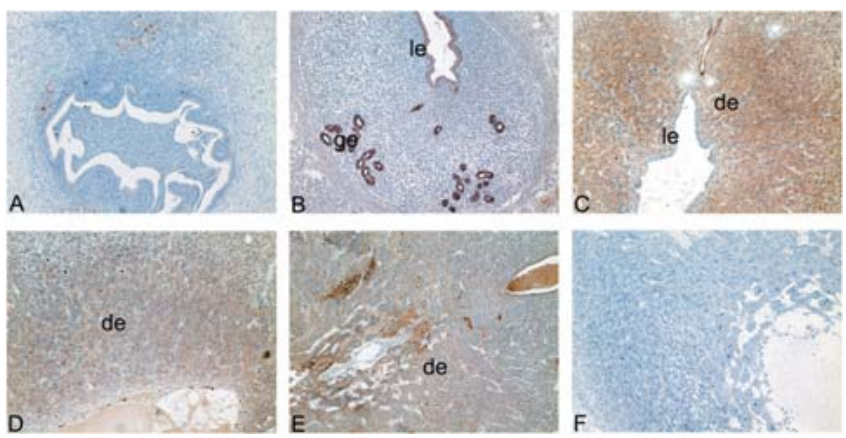

Fig. 3. Immunohistochemical analysis of Dkk2 protein in artificial decidualization uteri. This figure shows the expression patterns of Dkk2 in control uterine horns (A) and in the oil-induced deciduum on days 5 (B), 6 (C), 7 (D) and 8 (E) of pseudopregnancy. $\mathrm{F}$ is the negative control. Original magnification: $\times 200$.

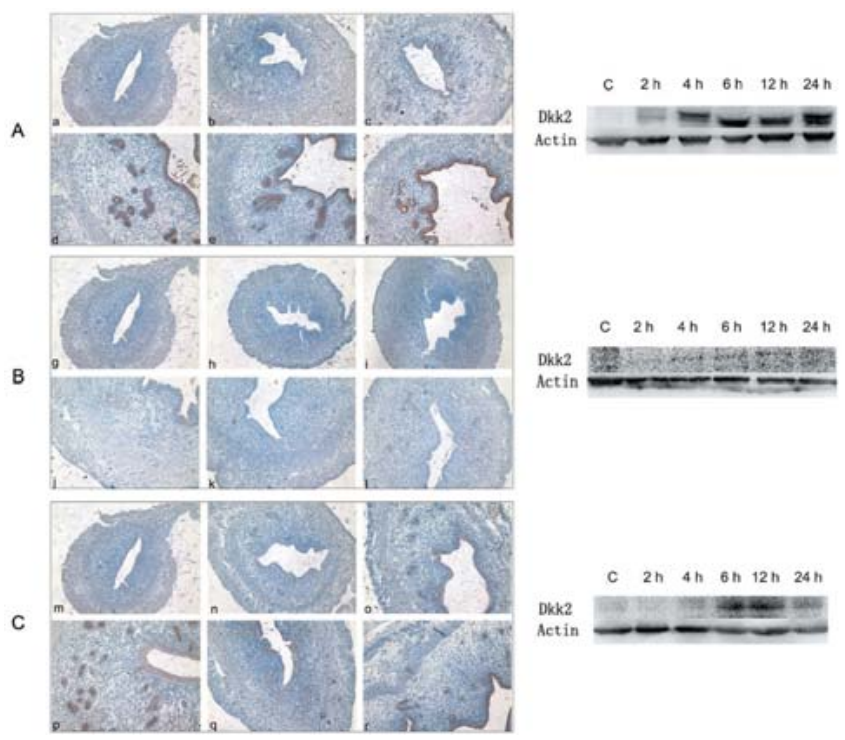

Fig. 4. Ovarian steroid hormone regulation of Dkk2 in the uteri of ovariectomized mice. Dkk2 was induced by E2 (A) and E2+P4 (C), but not by $\mathrm{P} 4$ (B) alone. This figure shows immunostaining analysis of Dkk2 in the uteri $2 \mathrm{~h} \mathrm{(b,} \mathrm{h} \mathrm{and} \mathrm{n),} 4 \mathrm{~h} \mathrm{(c,i} \mathrm{and} \mathrm{o),} 6 \mathrm{~h}$ (d, j and p), $12 \mathrm{~h} \mathrm{(e,} \mathrm{k} \mathrm{and} \mathrm{q)} \mathrm{and} 24 \mathrm{~h}(\mathrm{f}, \mathrm{l}$ and r) after steroid hormone treatment and in the control uterus horns (a, g and $\mathrm{m}$ ). Original magnification: $\times 200$. Western blotting (on the right side) also showed the same time-dependent expression pattern of Dkk2. $\beta$-actin was used as a loading control. Similar results were observed in two independent experiments.

change in the Dkk2 signal, which remained at a low level in the uteri. In the E2+P4 group (Fig. 4C), a similar effect was observed as seen in the E2 group. The western blot results further confirmed the results of immunohistochemistry.

Expression of active beta-catenin in the periimplantation period Previous studies have shown that Dkk2 function is related to

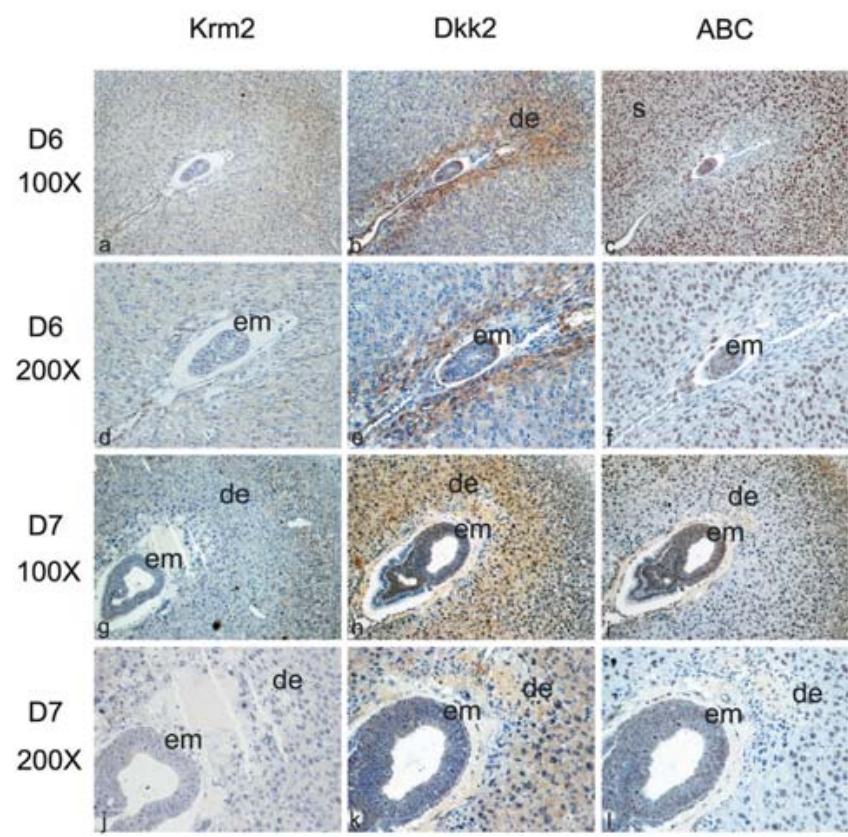

Fig. 5. Expression of Krm2, Dkk2 and active $\beta$-catenin (ABC) during decidualization. Immunostaining showed $\mathrm{Krm} 2$ (a, d, g and j), Dkk2 (b, e, h and k) and ABC (c, f, i and l) localization in the mouse uteri on days $6(\times 40, \times 200)$ and $7(\times 40, \times 200)$ of pregnancy. Em, embryo; de, deciduas; s, stroma.

canonical Wnt/beta-catenin signaling by binding to its receptor Kremen2 (Krm2). We first detected the localization of Krm2 during decidualization, but found that Krm2 is not colocalized with Dkk2 as shown in Fig. 5. In addition to investigating the relationship of Dkk2 and dephosphorylated (active) $\beta$-catenin (ABC) during implantation, we prepared serial sections of mouse periimplantation uterus and examined the expression of Dkk2 and active beta-catenin with immunostaining. As shown in Fig. 5, Dkk2 expression was restricted to around the implanting embryo on days 6 and 7. However, there was no or very weak expression of active beta-catenin in the same areas and strong staining in the outer layer of deciduas where there was no Dkk2.

\section{Discussion}

In this study, the expression and regulation patterns of Dkk2 in the mouse uterus during periimplantation were examined. The Dkk2 protein was highly detected in both the epithelial cells of the preimplantation uterus and deciduum of the postimplantation uterus, and these expression patterns were induced by estrogen and the process of decidualization separately.

Dkk2, a typical secretary protein, was strongly expressed in the uterine glandular epithelium on days 4 and 5 of pregnancy and then decreased on day 6 , and this was associated with uterine receptivity changes during this period. In fact, its expression pattern was somewhat similar to LIF, which has been demonstrated to play critical roles for uterine preparation and embryo implantation [18-20]. Indeed, there is evidence that Wnt signaling and LIF mediate over- 
lapping functions in maintenance of the pluripotency of mouse ES cells [21]. Furthermore, some members of the Wnt family, such as Wnt4 and sFRP4, have been reported to aberrantly express in the uterus of Lif null mice [6]. However, the potential interactions between Dkk2 and LIF signaling in the context of embryo implantation are still unknown and await further study.

Another characteristic feature of Dkk2 expression was that it markedly increased around implanting embryos with the initiation and expansion of decidualization. Decidualization is a biological process in which uterine endometrial stroma cells proliferate and differentiate into large epithelioid decidual cells. In the uteri of pregnant mice, the differentiating stromal cells surrounding the blastocysts initially formed a primary decidual zone (PDZ) on day 5 , and the secondary decidual zone (SDZ) began to be formed around the PDZ on day 6. Our results showed that expression of Dkk2 could be upregulated in the decidualizing stroma by both the embryo and oil, suggesting that there is tight correlation with the process of decidualization. Several genes have been proven to be critical for the process of decidualization, and some of them, such as $B M P 2$, share similar expressional features to Dkk2 [22]. BMP2 has been demonstrated to be a critical gene for decidual response in mice and humans [23-25]. Uterine specific ablation of BMP2 gene has resulted in complete infertility due to defective decidualization in mice [25]. Indeed, Dkk2 has been reported to regulate BMP2induced osteoblast differentiation through downregulation of Wnt/ beta-catenin signaling [23]. However, the exact role of $D k k 2$ and its hierarchical interaction with $B M P 2$ and other decidualization related genes requires further detailed exploration.

In the present study, we observed a significant increase of Dkk2 on day 4 of pregnancy, and this coincided with the preimplantation estrogen surge of E2 from corpora lutea. Using an established hormone treatment protocol, we further demonstrated that Dkk2 is upregulated by estrogen in the absence of an implanting embryo, with a peak at $6 \mathrm{~h}$ after E2 treatment. It has previously been demonstrated that several members of the Wnt signaling pathways are regulated by estrogen in the mouse uterus without the involvement of classical estrogen receptors (ERs), including Wnt4, Wnt5, frz2, sfrp2 and active beta-catenin [26]. Moreover, a report from Suzuki et al. showed that exposure to diethylstilbestrol (DES), an analog of E2, significantly induces expression of $D k k 2$ in mouse oviducts and uteri [27]. The results of the present study revealed another member of the Wnt signaling pathway that is regulated by E2. In mice, steroid hormone waves orchestrate the changes in the uterine epithelium. During early pregnancy, estrogen stimulates luminal and glandular epithelium proliferation and differentiation, making the uterus receptive to blastocysts so that implantation can be initiated. This effect is achieved through activation of a myriad of downstream target genes, and the exact role of Dkk2 in this complex system requires further investigation.

There is established evidence demonstrating that Wnt signaling plays critical roles in the process of implantation. For example, targeted gene deletion of Wnt7a in mice results in the complete absence of uterine glands and infertility [28], and Fzd4-/- mice fail to become pregnant and exhibit impaired corpora lutea formation and function [12]. Under normal conditions, formation of the primary and secondary decidual zones may be driven by Wnt pathway activity [29]. Dkk2 normally functions as an antagonist of canonical Wnt signaling by binding to Kremen2 (Krm2) to inhibit betacatenin activity, but other data shows that Dkk2 can activate rather than inhibit the $\mathrm{Wnt} / \beta$-catenin signaling pathway in Xenopus embryos [30]. In the present investigation, our colocalization experiment of Dkk2 and active $\beta$-catenin further suggested an inhibitory effect for Dkk2 against active $\beta$-catenin in the context of the decidualizing uterus. However, our results showed that Krm2 did not co-exist with Dkk2 in this area on days 6 and 7, which indicated that Dkk2 exerted its function without binding to Krm2 in this context. This phenomenon has been partially explained by the recent finding that Krm2 can function in the Wnt pathway in the absence of Dkks [30]. Given the results above, it is possible that Dkk2 acted as an inhibitor of canonical Wnt/ $\beta$-catenin in decidualization through a receptor(s) other than Krm2. Further detailed studies are needed to uncover the underlying mechanisms.

Our previous study demonstrated that Dkk1 participated in mouse decidualization [13], and the present study suggests that Dkk2 might be another member involved in this process. Indeed, there is much evidence suggesting that Dkks take part in brain, lens and tooth development in mice, all of which involve the process of epithelial-mesenchymal transformation [1, 17, 31, 32], and are hallmarks of uterine decidualization. In fact, $D k k 2$ homozygous mutant mice are viable and fertile, but smaller in size than their wild-type littermates. Mahua et al. [10] attributed this phenomenon to a bone density defect. In the present study, we suggested the alternative explanation that the Dkk2 mutant mouse could have defective implantation and decidualization that could potentially harm further development.

In conclusion, this study established the expression and regulation profiles of Dkk2 within the context of the mouse periimplantation uterus. Our data suggests that Dkk2 might play an important role by taking part in Wnt signaling during embryo implantation.

\section{Acknowledgements}

We thank Dr. Ping Zhao in our lab for proofreading of the manuscript and good suggestions. This study was supported by grants from the CAS Knowledge Innovation Program (KSCX2-YW-R080), National Basic Research Program of China (Grant No.2006CB944006) and National Natural Science Foundation of China (Grant No 30770819).

\section{References}

1. Diep DB, Hoen N, Backman M, Machon O, Krauss S. Characterisation of the Wnt antagonists and their response to conditionally activated Wnt signalling in the developing mouse forebrain. Brain Res Dev Brain Res 2004; 153: 261-270.

2. Hayashi K, Burghardt RC, Bazer FW, Spencer TE. WNTs in the ovine uterus: potential regulation of periimplantation ovine conceptus development. Endocrinology 2007; 148: 3496-3506.

3. Mohamed OA, Jonnaert M, Labelle-Dumais C, Kuroda K, Clarke HJ, Dufort D. Uterine Wnt/beta-catenin signaling is required for implantation. Proc Natl Acad Sci USA 2005; 102: 8579-8584.

4. Zheng P, Vassena R, Latham K. Expression and downregulation of WNT signaling pathway genes in rhesus monkey oocytes and embryos. Mol Reprod Dev 2006; 73: 667677

5. Popovici RM, Betzler NK, Krause MS, Luo M, Jauckus J, Germeyer A, Bloethner S, 
Schlotterer A, Kumar R, Strowitzki T, von WM. Gene expression profiling of human endometrial-trophoblast interaction in a coculture model. Endocrinology 2006; 147: 5662-5675.

6. Daikoku T, Song H, Guo Y, Riesewijk A, Mosselman S, Das SK, Dey SK. Uterine Msx-1 and Wnt4 signaling becomes aberrant in mice with the loss of leukemia inhibitory factor or Hoxa-10: evidence for a novel cytokine-homeobox-Wnt signaling in implantation. Mol Endocrinol 2004; 18: 1238-1250.

7. Xie H, Tranguch S, Jia X, Zhang H, Das SK, Dey SK, Kuo CJ, Wang H. Inactivation of nuclear Wnt-\{beta\}-catenin signaling limits blastocyst competency for implantation. Development 2008 (in press)

8. Miller C, Sassoon DA. Wnt-7a maintains appropriate uterine patterning during the development of the mouse female reproductive tract. Development 1998; 125: 32013211.

9. van HG, van WS, Farih-Sips H, van BR, Lowik CW, Karperien M. Downregulation of Wnt signaling by increased expression of Dickkopf- 1 and -2 is a prerequisite for late-stage osteoblast differentiation of KS483 cells. J Bone Miner Res 2005; 20: 18671877.

10. Mukhopadhyay M, Gorivodsky M, Shtrom S, Grinberg A, Niehrs C, Morasso MI, Westphal H. Dkk2 plays an essential role in the corneal fate of the ocular surface epithelium. Development 2006; 133: 2149-2154.

11. Sick S, Reinker S, Timmer J, Schlake T. WNT and DKK determine hair follicle spacing through a reaction-diffusion mechanism. Science 2006; 314: 1447-1450.

12. Hsieh M, Boerboom D, Shimada M, Lo Y, Parlow AF, Luhmann UF, Berger W, Richards JS. Mice null for Frizzled4 (Fzd4-/-) are infertile and exhibit impaired corpora lutea formation and function. Biol Reprod 2005; 73: 1135-1146.

13. Li J, Liu WM, Cao YJ, Peng S, Zhang Y, Duan EK. Roles of Dickkopf-1 and its receptor Kremen1 during embryonic implantation in mice. Fertil Steril 2007 (in press).

14. Peng S, Li J, Miao C, Jia L, Hu Z, Zhao P, Li J, Zhang Y, Chen Q, Duan E. Dickkopf-1 secreted by decidual cells promotes trophoblast cell invasion during murine placentation. Reproduction 2008; 135: 367-375.

15. Adachi S, Yamada S, Takatsu Y, Matsui H, Kinoshita M, Takase K, Sugiura H, Ohtaki T, Matsumoto H, Uenoyama Y, Tsukamura H, Inoue K, Maeda K. Involvement of anteroventral periventricular metastin/kisspeptin neurons in estrogen positive feedback action on luteinizing hormone release in female rats. J Reprod Dev 2007; 53: 367-378.

16. Li J, Zhang JV, Cao YJ, Zhou JX, Liu WM, Fan XJ, Duan EK. Inhibition of the betacatenin signaling pathway in blastocyst and uterus during the window of implantation in mice. Biol Reprod 2005; 72: 700-706.

17. Monaghan AP, Kioschis P, Wu W, Zuniga A, Bock D, Poustka A, Delius H, Niehrs C. Dickkopf genes are co-ordinately expressed in mesodermal lineages. Mech Dev 1999; 87: 45-56.

18. Song H, Lim H, Das SK, Paria BC, Dey SK. Dysregulation of EGF family of growth factors and COX-2 in the uterus during the preattachment and attachment reactions of the blastocyst with the luminal epithelium correlates with implantation failure in LIFdeficient mice. Mol Endocrinol 2000; 14: 1147-1161.

19. Stewart CL, Kaspar P, Brunet LJ, Bhatt H, Gadi I, Kontgen F, Abbondanzo SJ. Blastocyst implantation depends on maternal expression of leukaemia inhibitory factor. Nature 1992; 359: 76-79.

20. Wakitani S, Hondo E, Phichitraslip T, Stewart CL, Kiso Y. Upregulation of Indian hedgehog gene in the uterine epithelium by leukemia inhibitory factor during mouse implantation. J Reprod Dev 2008; 54: 113-116.

21. Ogawa K, Nishinakamura R, Iwamatsu $Y$, Shimosato D, Niwa H. Synergistic action of Wnt and LIF in maintaining pluripotency of mouse ES cells. Biochem Biophys Res Commun 2006; 343: 159-166.

22. Paria BC, Ma W, Tan J, Raja S, Das SK, Dey SK, Hogan BL. Cellular and molecular responses of the uterus to embryo implantation can be elicited by locally applied growth factors. Proc Natl Acad Sci USA 2001; 98: 1047-1052.

23. Fujita K, Janz $\mathbf{S}$. Attenuation of WNT signaling by DKK-1 and -2 regulates BMP2induced osteoblast differentiation and expression of OPG, RANKL and M-CSF. Mol Cancer 2007; 6: 71.

24. Li Q, Kannan A, Wang W, Demayo FJ, Taylor RN, Bagchi MK, Bagchi IC. Bone morphogenetic protein 2 functions via a conserved signaling pathway involving Wnt 4 to regulate uterine decidualization in the mouse and the human. J Biol Chem 2007; 282 31725-31732

25. Lee KY, Jeong JW, Wang J, Ma L, Martin JF, Tsai SY, Lydon JP, DeMayo FJ. Bmp2 is critical for the murine uterine decidual response. Mol Cell Biol 2007; 27: 5468-5478.

26. Hou X, Tan Y, Li M, Dey SK, Das SK. Canonical Wnt signaling is critical to estrogenmediated uterine growth. Mol Endocrinol 2004; 18: 3035-3049.

27. Suzuki A, Urushitani H, Sato T, Kobayashi T, Watanabe H, Ohta Y, Iguchi T. Gene expression change in the Mullerian duct of the mouse fetus exposed to diethylstilbestrol in utero. Exp Biol Med (Maywood) 2007; 232: 503-514.

28. Tulac S, Nayak NR, Kao LC, Van WM, Huang J, Lobo S, Germeyer A, Lessey BA, Taylor RN, Suchanek E, Giudice LC. Identification, characterization, and regulation of the canonical Wnt signaling pathway in human endometrium. J Clin Endocrinol Metab 2003; 88: 3860-3866.

29. Carson DD. Uterine sensing of the embryo. Proc Natl Acad Sci USA 2005; 102: 83978398.

30. Wu W, Glinka A, Delius H, Niehrs C. Mutual antagonism between dickkopf1 and dickkopf2 regulates Wnt/beta-catenin signalling. Curr Biol 2000; 10: 1611-1614.

31. Ang SJ, Stump RJ, Lovicu FJ, McAvoy JW. Spatial and temporal expression of Wnt and Dickkopf genes during murine lens development. Gene Expr Patterns 2004; 4: 289295.

32. Fjeld K, Kettunen P, Furmanek T, Kvinnsland IH, Luukko K. Dynamic expression of Wnt signaling-related Dickkopf1, -2 , and -3 mRNAs in the developing mouse tooth Dev Dyn 2005; 233: 161-166. 